\title{
Green Synthesis of Magnetite Nanoparticles Using Aqueous Leaves Extracts of Azadirachta indica and Its Application for the Removal of As(V) from Water
}

\author{
Kshama Parajuli*, Aravind Kumar Sah, Hari Paudyal ${ }^{*}$ \\ Central Department of Chemistry, Tribhuvan University, Kirtipur, Kathmandu, Nepal \\ Email: ^haripaudyal9@gmail.com, ^kshamaparajuli@gmail.com
}

How to cite this paper: Parajuli, K., Sah, A.K. and Paudyal, H. (2020) Green Synthesis of Magnetite Nanoparticles Using Aqueous Leaves Extracts of Azadirachta indica and Its Application for the Removal of $\mathrm{As}(\mathrm{V})$ from Water. Green and Sustainable Chemistry, 10, 117-132.

https://doi.org/10.4236/gsc.2020.104009

Received: October 3, 2020

Accepted: November 24, 2020

Published: November 27, 2020

Copyright $\odot 2020$ by author(s) and Scientific Research Publishing Inc. This work is licensed under the Creative Commons Attribution International License (CC BY 4.0).

http://creativecommons.org/licenses/by/4.0/

(c) (i) Open Access

\begin{abstract}
Because of various disadvantages of chemical synthesis processes, these days people are attracting towards green synthesis processes as it is devoid of toxic by-products, cost-effective and eco-friendly. In this study, a simple green synthesis method is applied for the synthesis of magnetite $\left(\mathrm{Fe}_{3} \mathrm{O}_{4}\right)$ nanoparticles (MNPs) by co-precipitation of $\mathrm{FeCl}_{3} \cdot 6 \mathrm{H}_{2} \mathrm{O}$ and $\mathrm{FeSO}_{4} \cdot 7 \mathrm{H}_{2} \mathrm{O}$ in the molar ratio of 2:1 using Azadirachta indica leaves extract under nitrogen environment. FTIR, XRD, SEM etc. were used to characterize the synthesized MNPs. Batch adsorption experiments were carried out to determine adsorption equilibrium of $\mathrm{As}(\mathrm{V})$ as a function of $\mathrm{pH}$, adsorbent dose, contact time and different initial concentrations. Kinetics results were best described by pseudo-second order model with rate constant value $0.0052 \mathrm{~g} /(\mathrm{mg} \cdot \mathrm{min})$. The equilibrium adsorption isotherm was best fitted with Langmuir adsorption isotherm model. The maximum adsorption capacity was found to be 62.89 $\mathrm{mg} / \mathrm{g}$ at $\mathrm{pH}$ 2. MNPs showed a high affinity for $\mathrm{As}(\mathrm{V})$ and avoids filtration for solid-liquid separation, thus it would be employed as a promising material for the removal of $\mathrm{As}(\mathrm{V})$ from water.
\end{abstract}

\section{Keywords}

Green Synthesis, Magnetite Nanoparticles (MNPs), Azadirachta indica Leaves Extract, As(V) Adsorption

\section{Introduction}

Contamination of water bodies due to the presence of certain heavy metal ions is increasing day by day because of increased population and industrialization. Due 
to their toxicity, non-biodegradability and long-time persistent nature, their removal becomes an absolute necessity. Moreover, the persistent nature makes it accumulate in the food chains which with time reach harmful levels in living beings, resulting in serious health hazards such as irritation in lungs and stomach, cancer of different organs, low growth rates in plants and death of animals, etc. [1] [2]. Hence, heavy metals poisoning of water bodies is a serious world health issue. Among such noxious heavy metals, arsenic is considered as one of the most toxic heavy metal and due to its toxic nature, world health organization has set its limit as $10 \mu \mathrm{g} \cdot \mathrm{L}^{-1}$ in drinking water [3] [4]. The main source of arsenic in water is due to the natural dissolution of ores and minerals that contain arsenic, industrial discharges, agricultural use of arsenical herbicides and pesticides [5] [6].

Removal of arsenic from drinking water can be accomplished by several physiochemical methods such as adsorption, ion exchange, precipitation, filtration and coagulation, reverse osmosis and electro dialysis etc. [7]. Among them, adsorption is considered as one of the best methods available to eliminate contaminants from water bodies because it can reduce the pollutants concentration to trace levels and its easiness of operation [8]. Although, different adsorbing material such as activated carbon, oxides and hydroxides of metals, polymeric resins, clay minerals and zeolites etc. have been reported for the arsenic removal, in recent days different nanomaterials have been reported as promising materials for removal of toxic heavy metals from polluted water [9] [10]. Moreover, it is suggested that Nanotechnology is considered to play a crucial role in providing clean and affordable water to meet human demands [11]. The iron based NPS especially magnetite nanoparticles (MNPs) has attracted attention of many researchers in this field because of high affinity of arsenic toward iron due to high stability of arsenic-iron bond [12]. More interestingly, due to its magnetic property, it can be efficiently separated from wastewater by using magnetic separators avoiding the filtration process, which represents a difficulty in using other nanosized materials at the treatment of great volumes of wastewaters in environmental remediation [13].

Although different physical, chemical and biological synthetic routes have been applied for preparation of MNPs [14] [15], these days people are attracting towards bio (green) synthesis processes as it is devoid of toxic by-products, cost-effective and eco-friendly, biocompatible and low toxicity and antimicrobial effectiveness etc. [16] [17]. Hence, green synthesis of the NPs is taken as need of today as it can address the green chemistry principles [18]. Biosynthesis can be carried out either by using different microrganisms or by using extract of different plants parts such as extract of root, stem, leaves, bark, flower and seeds etc. [16] [19] [20]. Moreover, plant based synthesis are more popular as they are natural, renewable, safe to handle and easily accessible [21]. Plant extracts contain different metabolites (phytochemicals) like terpenoids, phenols, proteins or carbohydrates etc., which are directly responsible to reduce the metallic salts to NPs and also act as capping/stabilizing agents by hampering the aggregation of 
NPs [22]. Hence, in the present study, utilization of aqueous leaves extract of Azadirachta indica (Neem) for the synthesis of MNPs to remove As(V) from water has been explored.

\section{Materials and Methods}

\subsection{Green Synthesis of Magnetite Nanoparticles (MNPs)}

Azadirachta indica (Neem) fresh leaves were collected from the locality of Tarai region of Nepal and were washed thoroughly with water. Green leaves were dried under shade for 7 days and made power using mortar and pestle. Thus prepared leaves powder was used to prepare leaves aqueous extract as described elsewhere [23]. Conventionally, magnetite $\mathrm{Fe}_{3} \mathrm{O}_{4}$ - NPs were prepared by adding a base to an aqueous mixture of ferric $\left(\mathrm{Fe}^{3+}\right)$ and ferrous $\left(\mathrm{Fe}^{2+}\right)$ at a 2:1 molar ratio [29]. Hence in the present study, MNPs were prepared by the co-precipitation method using ferric chloride hexahydrate, $\left(\mathrm{FeCl}_{3} \cdot 6 \mathrm{H}_{2} \mathrm{O}, 97 \%\right.$, Loba Chemie) and ferrous sulfate heptahydrate $\left(\mathrm{FeSO}_{4} \cdot 7 \mathrm{H}_{2} \mathrm{O}, 98 \%\right.$, Thermo Fisher Scientific) in the ratio of $2: 1$ at $45^{\circ} \mathrm{C}$ under nitrogen atmosphere to prevent the unwanted oxidation and aqueous ammonia $\left(\mathrm{NH}_{4} \mathrm{OH}, 25 \%\right.$, Merck Life Science Pvt. Ltd) was added quickly into the reaction mixture solution under stirring condition until the $\mathrm{pH}$ value of the solution reached to $10-11$. About $5 \mathrm{ml}$ of leaves extract was added into the mixture and it was heated at $80^{\circ} \mathrm{C}$ for 1 hour. After 1 hour, resulting MNPs were collected from the solution by external magnet and washed several times by oxygen removed water and finally with ethanol, then dried under vacuum conditions at $60^{\circ} \mathrm{C}$ for $12 \mathrm{hrs}$. The possible reaction for the formation of MNPs is given as follows [24].

$$
\begin{gathered}
\mathrm{Fe}^{3+}+3 \mathrm{OH}^{-} \rightarrow \mathrm{Fe}(\mathrm{OH})_{3} \\
\mathrm{Fe}(\mathrm{OH})_{3} \rightarrow \mathrm{FeOOH}+\mathrm{H}_{2} \mathrm{O} \\
\mathrm{Fe}^{2+}+2 \mathrm{OH}^{-} \rightarrow \mathrm{Fe}(\mathrm{OH})_{2} \\
2 \mathrm{FeOOH}+\mathrm{Fe}(\mathrm{OH})_{2} \rightarrow \mathrm{Fe}_{3} \mathrm{O}_{4} \downarrow+2 \mathrm{H}_{2} \mathrm{O}
\end{gathered}
$$

The scheme for the green synthesis of MNPs is given in Figure 1 below.

\subsection{Determination of $\mathrm{pH} \mathrm{Pzc}$}

In this study, $\mathrm{pH}_{\mathrm{PzC}}$ is determined by $\mathrm{pH}$ drift method [25]. Different initial $\mathrm{pH}$ solutions (2 - 11) with background electrolyte of $0.01 \mathrm{M}$ sodium chloride $(\mathrm{NaCl}$, 99.5\%, Thermo Fisher Scientific) were prepared using sodium hydroxide (NaOH, 97\%, Thermo Fisher Scientific) and hydrochloric acid ( $\mathrm{HCl}$, Qualigens Fine Chemicals). The final $\mathrm{pH}$ of the solutions with the dispersed adsorbent (25 $125 \mathrm{~mL}$ of respective $\mathrm{pH}$ solution) was measured using glass electrode (Deluxe pH Meter) after $24 \mathrm{hrs}$.

\subsection{Batch adsorption Study}

Batch sorption experiments as functions of $\mathrm{pH}(2-10)$, adsorbent dosage $(0.025$ 


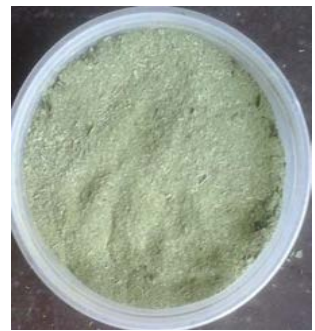

Azadirachta indica leaves powder

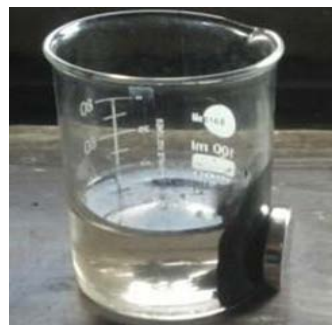

Separation of Magnetite nanoparticles (MNPs)

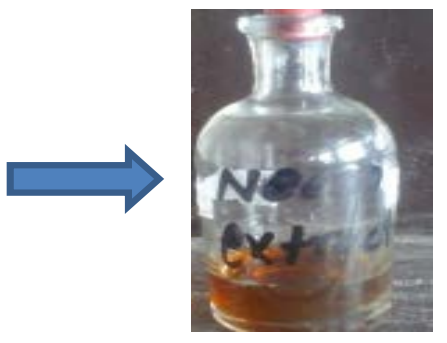

Aqueous leaf extract of Azadirachta indica

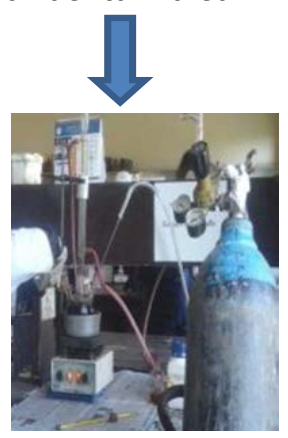

Synthesis of MNPs under $\mathrm{N}_{2}$ atmosphere

Figure 1. Experimental photograph for the preparation of MNPs.

- 3) g/L, contact time (10 - 240) min (kinetics study), as well as effect of initial concentrations of adsorbate $(10-100) \mathrm{mg} / \mathrm{L}$ (isotherm study) were carried out. The solutions of $\mathrm{As}(\mathrm{V})$ comprised of disodium hydrogen arsenate $\left(\mathrm{Na}_{2} \mathrm{HAsO}_{4} \cdot 7 \mathrm{H}_{2} \mathrm{O}\right.$, Fine Chemical Ltd) were taken into Erlenmeyer flasks. After $\mathrm{pH}$ adjustment, a known quantity of adsorbent was added and finally, metal bearing suspensions were kept under magnetic stirring. After shaking, the suspension was allowed to settle using external magnet and the residual adsorbent with metal ions was filtered using Whatman 42 filter paper. The amount of metal ions adsorbed $\left(Q_{e}\right)$ and percentage removal efficiency of the adsorbent is determined by using following relations:

$$
\begin{gathered}
Q_{e}=\frac{\left(C_{o}-C_{e}\right) V}{m} \\
R(\%)=\frac{C_{o}-C_{e}}{C_{o}} \times 100
\end{gathered}
$$

where $C_{o}$ and $C_{e}$ are initial and equilibrium metal ion concentrations respectively in $\mathrm{mg} / \mathrm{L}, V$ is the volume of metal solution in $\mathrm{L}, m$ is the weight of adsorbent in $\mathrm{g}, Q_{e}(\mathrm{mg} / \mathrm{g})$ is the amount of adsorbate adsorbed at equilibrium and $R(\%)$ is the percentage of metal ion adsorption from the solution. As $(\mathrm{V})$ concentration was measured molybdenum blue method by using spectrophotometer (Electronic, India, Model No 2306). Absorbance of the blue colored solution was measured at $\lambda=840 \mathrm{~nm}$ after 60 min against blank and the corresponding $\mathrm{As}(\mathrm{V})$ concentrations were measured by molybdenum blue method (by) using spectrophotometer. 


\section{Results and Discussion}

\section{Characterizations of Adsorbents}

\section{1) Functional group analysis by FTIR spectroscopy}

FTIR provides information regarding the shifting/changing of some surface functional groups that might have participated in the chemical modification. Figure 2 showed the FTIR spectra of leaves extract of Azadirachta indica and synthesized MNPs. In the case of Azadirachta indica leaves extract (Figure 2(a)), a broad peak at $3289 \mathrm{~cm}^{-1}$ was observed which is attributed due to $\mathrm{O}-\mathrm{H}$ stretching vibration of phenolic compounds. The peak located at around $1640 \mathrm{~cm}^{-1}$ is ascribed due to $\mathrm{C}=\mathrm{O}$ stretching vibration [26] [27]. However in MNPs (Figure 2(b)), there is a shift of the band from $1640 \mathrm{~cm}^{-1}$ to $1604 \mathrm{~cm}^{-1}$ and was attributed to the binding of a $\mathrm{C}=\mathrm{O}$ group with the nanoparticles [24]. Literature shows that the presence of inorganic lattice vibration appears in the range of $400-700 \mathrm{~cm}^{-1}$. Appearance of two entirely new peaks at around 547 and $404 \mathrm{~cm}^{-1}$ in $\mathrm{Fe}_{3} \mathrm{O}_{4} \mathrm{NPs}$ can be attributed due to the Fe-O stretching band [28] [29] [30], which provides the strong evidence that magnetite particles (MPs) were formed with the aid of extract of Azadirachta indica leaves.

\section{2) Identification of MNPs phase and crystalline size}

The XRD pattern of aqueous leaves extract of Azadirachta indica and synthesized MNPs is shown in Figure 3 The diffraction peaks were found at $2 \theta$ values around 30.31, 35.92, 43.6, 57.38, and 62.96 which could be accounting for crystal planes (220), (311), (400), (333), and (440) of crystalline MNPs respectively. The observed XRD pattern was in good agreement with the standard XRD pattern of magnetite (card JCPDS \# 89-4319). Moreover, the pattern also showed that 311 plane is a major plane with the majority of the particles having faced centered cubic (FCC) crystalline structure.

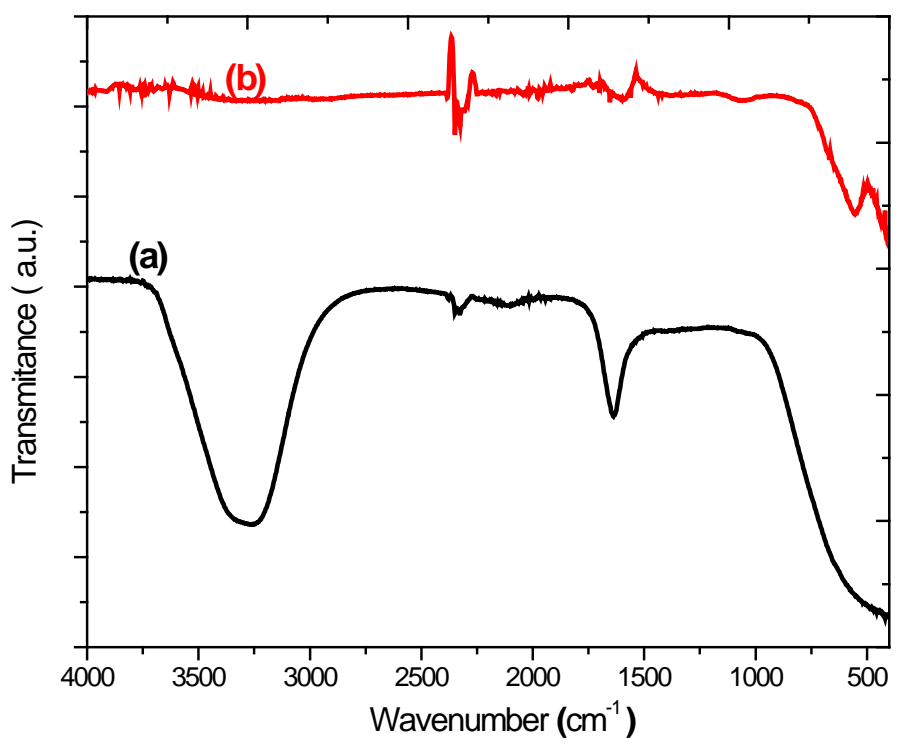

Figure 2. FTIR spectra of (a) aqueous Azadirachta indica leaves extract (b) synthesized MNPs. 


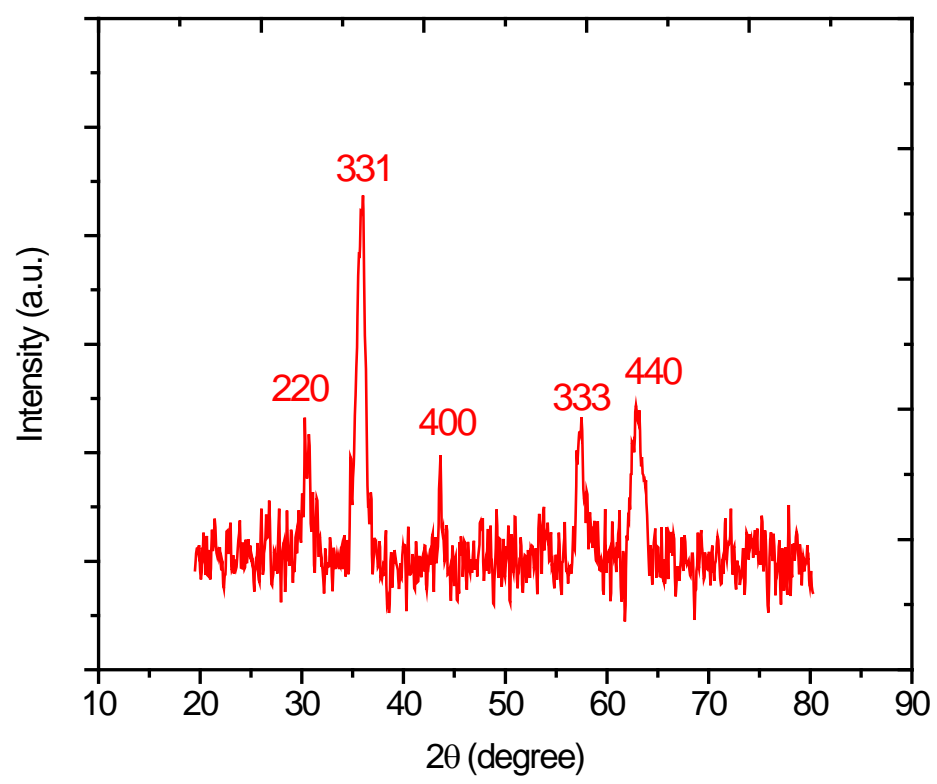

Figure 3. X-ray diffraction (XRD) pattern of magnetite $\left(\mathrm{Fe}_{3} \mathrm{O}_{4}\right) \mathrm{NPs}$.

The crystallite size $(D)$ of the MNPs was determined by using Debye-Scherrer's equation as

$$
D=\frac{k \lambda}{\beta \cos \theta}
$$

where $D$ is the particle size of the crystal, $k$ is a Sherrer constant (0.9), $\lambda$ is the X-ray wavelength ( $\lambda=1.541 \AA), \beta$ is the full width at half maxima (FWHM) and $\theta$ is the Braggs diffraction angle corresponding to the lattice plane. The average particle size of the particles by using Scherrer's equation was found to be $8.4 \mathrm{~nm}$, indicating the formation of MNPs.

\section{3) Determination of surface morphology of synthesized MNPs}

The surface morphology of the particles was carried out by the Scanning Electron Microscopy (SEM) (FE-SEM, Hitachi S-7400) and the results at different magnification are shown in Figure 4(a) and Figure 4(b). From these images, the structures of MNPs are spherical, uniform and in the nanometer ranges (less than $100 \mathrm{~nm}$ ). Moreover, in some place NPs were aggregated and forming large aggregate. Similar SEM image is reported when hydrothermal synthesis of MNPs was carried out using aloe vera (Aloe barbadensis Miller) plant extract solution [31].

\section{4) Effect of $\mathrm{pH}$ and $\mathrm{As}(\mathrm{V})$ adsorption mechanism}

The $\mathrm{pH}$ of a solution is taken as one of the most important parameters in the study of the adsorption of metal ions onto adsorbent as chemical speciation of adsorbate as well as surface charge of the adsorbent are highly $\mathrm{pH}$ dependent in aqueous medium. Figure 5 shows the effect of $\mathrm{pH}$ on $\mathrm{As}(\mathrm{V})$ removal by MNPs. As can be observed from the result of this figure that maximum adsorption was observed at $\mathrm{pH} 2$ then it was observed to be decreased with the further increase of equilibrium $\mathrm{pH}$. At low $\mathrm{pH}$, the surface of MNPs is positively charged so that 


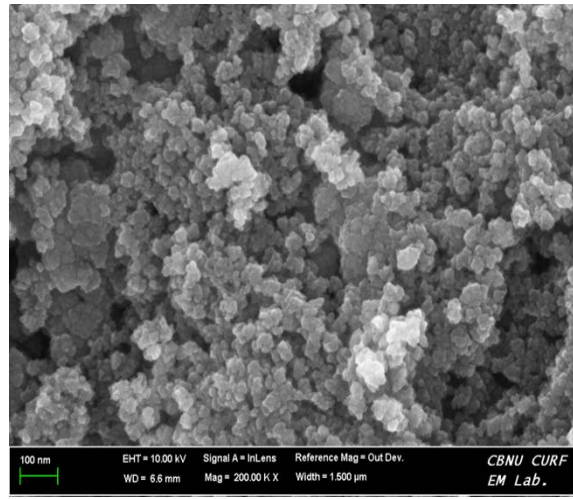

(a)

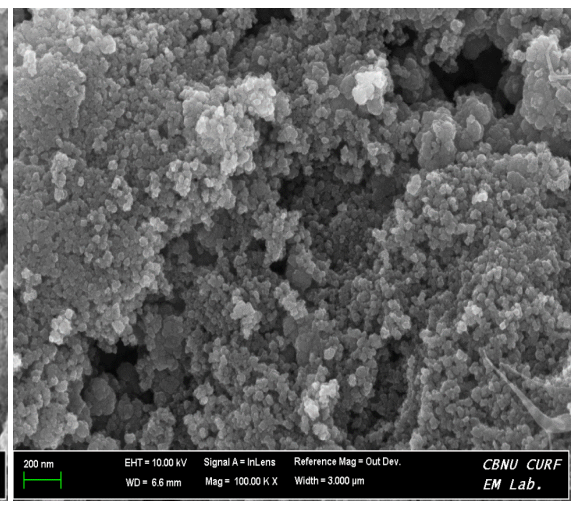

(b)

Figure 4. SEM images of MNPs at different magnifications, (a) 100×, and (b) 200×.

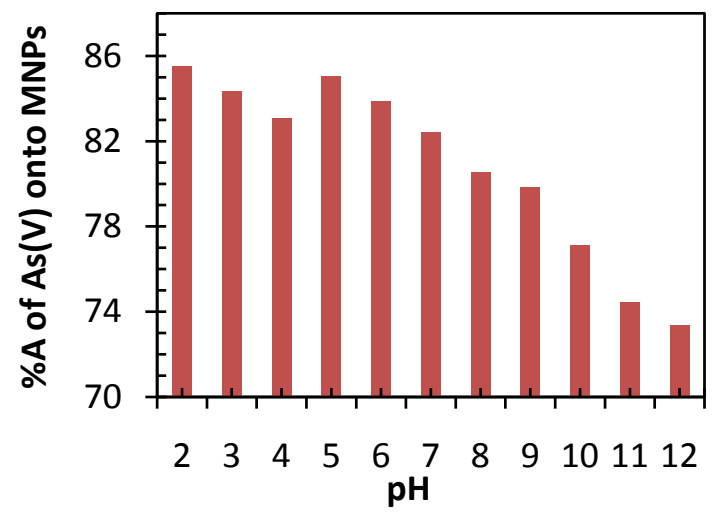

Figure 5. Effect of $\mathrm{pH}$ on $\mathrm{As}(\mathrm{V})$ removal by magnetite $\left(\mathrm{Fe}_{3} \mathrm{O}_{4}\right) \mathrm{NPs}$.

interaction of negatively charged species of $\mathrm{As}(\mathrm{V})$ is more favorable, resulting in the increasing of \% adsorption. At high $\mathrm{pH}$, the \% removal of $\mathrm{As}(\mathrm{V})$ was observed to be decreased which may be reasonably attributed due to the competition of hydroxyl ion with $\mathrm{As}(\mathrm{V})$ anion for the same active sites. Such nature of adsorption behavior is in agreement with previous studies [32] [33]. High sorption performance of investigated MNPs at low $\mathrm{pH}$ can be explained as follows.

The $\mathrm{pH}_{\mathrm{PZC}}$ of the MNPs was found to be $\mathrm{pH} 7.5$ from Figure 6. Hence below pHpzc, surface charge of the MNPs is expected to be positive. As(V) exists as $\mathrm{H}_{3} \mathrm{AsO}_{4}(<2 \mathrm{pH}), \mathrm{H}_{2} \mathrm{AsO}_{4}^{-}(2-6) \mathrm{pH}, \mathrm{HAsO}_{4}^{2-}(6-11.5) \mathrm{pH}$ and $\mathrm{AsO}_{4}^{3-}$ $(>11.5) \mathrm{pH}$ [34]. The maximum uptake of $\mathrm{As}(\mathrm{V})$ by MNPs was observed at $\mathrm{pH} 2$ where adsorption of monovalent species of $\mathrm{As}(\mathrm{V})$ occurred due to electrostatic attraction.

\section{5) Effect of contact time}

Kinetic studies determine the equilibrium time and binding rate of adsorbate on the adsorbent. The adsorption kinetics experiments were performed at the optimum $\mathrm{pH}$ at desired period of contact time of $\mathrm{As}(\mathrm{V})$ ion by equilibrating in solution. A rapid initial adsorption followed by gradual uptake and approach equilibrium at the end of adsorption process was observed as shown in Figure 7. The greater number of $\mathrm{As}(\mathrm{V})$ ions were available to adsorb onto MNPs so that 


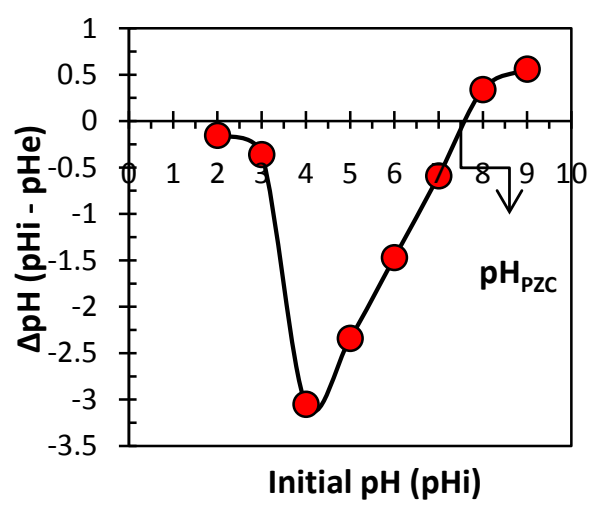

Figure 6. Difference in $\mathrm{pH}$ against initial $\mathrm{pH}$ for the determination of $\mathrm{pH}_{\mathrm{PZC}}$ plot of MNPs.

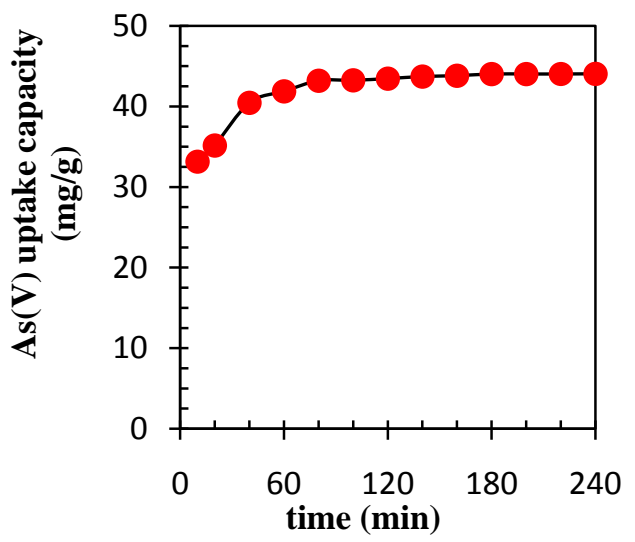

Figure 7. A plot of the effect of contact time on the removal of As(V) onto MNPs.

adsorption rate was rapid at the beginning, then it was gradually adsorbed and finally attains equilibrium after 90 minutes. Although adsorption equilibrium was attained at 90 minutes but for the subsequent experiments, solid liquid mixture was shaken for $24 \mathrm{~h}$ to ensure complete equilibrium. Moreover, the kinetic data obtained were analyzed using linear pseudo-first order and the pseudo-second order equations respectively.

$$
\begin{gathered}
\log \left(Q_{e}-Q_{t}\right)=\log Q_{e}-\frac{K_{1}}{2.303} t \\
\frac{t}{Q_{t}}=\frac{1}{K_{2} Q_{e}^{2}}+\frac{1}{Q_{e}} t
\end{gathered}
$$

where $Q_{e}$ and $Q_{t}$ are the amount of metal adsorbed $(\mathrm{mg} / \mathrm{g})$ at equilibrium and at any contact time $t(\mathrm{~min})$. Similarly, $K_{1}$ and $K_{2}$ are pseudo-first order and pseudo-second order rate constants respectively. Two different plots of $\log \left(Q_{e}-Q_{t}\right)$ versus reaction time $(t)$ (Figure $8(\mathrm{a})$ ) and $t / Q_{t}$ versus reaction time (Figure $8(\mathrm{~b})$ ) were drawn to evaluate respective rate constants and coefficient of determination $\left(R^{2}\right)$ for both types of kinetic models. The rate of reaction as well as the $\mathrm{As}(\mathrm{V})$ uptake capacity from the slopes and intercepts of Figure 8(a) and Figure 8(b) plots are shown in Table 1 . The $A s(V)$ uptake capacity determined from 


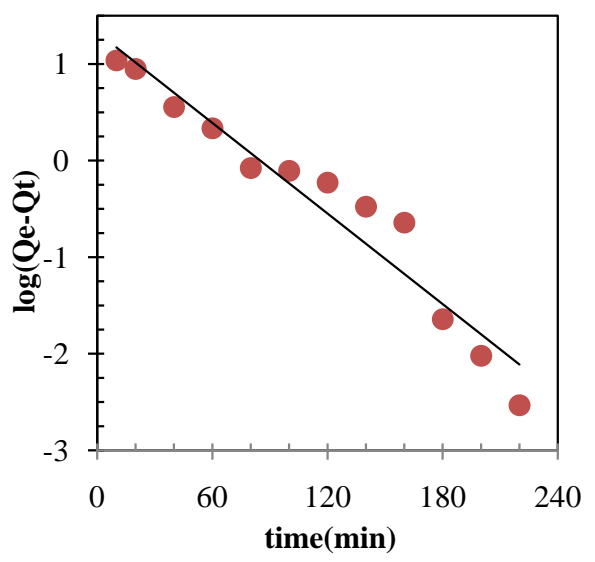

(a)

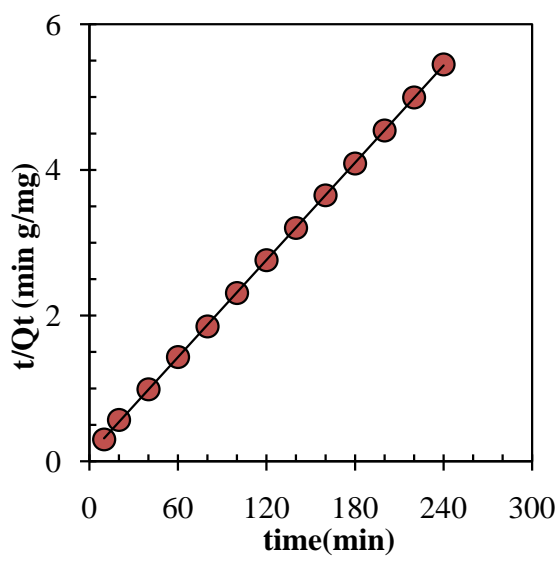

(b)

Figure 8. Modeling of kinetic data by pseudo (a) $1^{\text {st }}$ order and, (b) $2^{\text {nd }}$ order model on the removal of $\mathrm{As}(\mathrm{V})$.

Table 1. Evaluated pseudo $1^{\text {st }}$ and $2^{\text {nd }}$ order kinetic parameters for adsorption of $A s(V)$ onto MNPs.

\begin{tabular}{ccccccc}
\hline & \multicolumn{3}{c}{ Pseudo-first order model } & \multicolumn{3}{c}{ Pseudo-second order model } \\
\cline { 2 - 7 }$Q_{\text {exper. }}(\mathrm{mg} / \mathrm{g})$ & $K_{1}\left(\mathrm{~min}^{-1}\right)$ & $Q_{e 1}(\mathrm{mg} / \mathrm{g})$ & $R^{2}$ & $\begin{array}{c}\left(K_{2} \times 10^{-2}\right) \\
\left(\mathrm{g} \cdot \mathrm{min}^{-1} \cdot \mathrm{mg}^{-1}\right)\end{array}$ & $Q_{e 2}(\mathrm{mg} / \mathrm{g})$ & $R^{2}$ \\
\hline $\mathbf{4 4 . 0 4}$ & 0.036 & 8.11 & 0.93 & 0.52 & 45.46 & 0.99 \\
\hline
\end{tabular}

pseudo-second order model $(45.46 \mathrm{mg} / \mathrm{g})$ is very close to the experimental value $(44.03 \mathrm{mg} / \mathrm{g})$ than pseudo-first order model. Moreover, the correlation coefficient values of pseudo-first order and pseudo-second order models are 0.93 and 0.99 respectively. Hence, it is suggested that the pseudo-second order model best describes the equilibrium adsorption data of $\mathrm{As}(\mathrm{V})$ adsorption onto MNPs and the rate constant was found to be $0.0052 \mathrm{~g} \mathrm{mg}^{-1} \cdot \mathrm{min}^{-1}$.

\section{6) Adsorption isotherm of $\mathrm{As}(\mathrm{V})$ ion}

Adsorption isotherm is a graphical representation of the amount of the adsorbate adsorbed per unit mass of the adsorbent as a function of the amount of the adsorbate left in bulk solution at equilibrium at a given temperature. In order to study the dominant adsorption mechanism and to compute various adsorption parameters, different isotherm models such as Langmuir, Freundlich, Dubinin-Radushkevich, Temkinl, Flory-Huggins, and Hill isotherm model etc. have been developed [30]. Langmuir and Freundlich adsorption isotherm models of adsorption are well known among them. Experimental adsorption data were fitted by the least square method to linearly transformed Freundlich and Langmuir adsorption isotherms equations (Equation (6)) and (Equation (7)) respectively.

$$
\begin{gathered}
\log Q_{e}=\log K_{F}+\frac{1}{n} \log C_{e} \\
\frac{C_{e}}{Q_{e}}=\frac{1}{Q_{m} b}+\frac{C_{e}}{Q_{m}}
\end{gathered}
$$


Using (Equation (6)), a plot of $\log Q_{e}$ versus $\log C_{e}$ yielded a linear Freundlich plot (Figure 9(b)) and the intercept and slope of the plot give the empirical constants $K_{f}$ and $n$ which is related to adsorption capacity and adsorption affinity of the adsorbent respectively. Similarly using (Equation (7)), a plot of $C_{e} / Q_{e}$ versus $C_{e}$ resulted in a linear Langmuir plot (Figure 9(a)) and from the slope and intercept the values of $Q_{\max }\left(\mathrm{mg} \cdot \mathrm{g}^{-1}\right)$, the maximum adsorption capacity corresponding to complete monolayer coverage and $b\left(\mathrm{~L} \cdot \mathrm{mg}^{-1}\right)$, the affinity of the binding sites, also called the Langmuir constant was obtained. The evaluated isotherms parameters for both the models are listed in Table 2.

The experimental data fitted well with Langmuir model. Further, observed correlation coefficient of Langmuir plot $\left(R^{2}=0.98\right)$ is higher than that of Freundlich plot $\left(R^{2}=0.87\right)$ and smaller $\chi^{2}$ value for Langmuir model than Feundlich model suggests the experimental data best fitted with the Langmuir model. The value of Freundlich constant $(1 / n)$ and Langmuir equilibrium parameter $\left(R_{L}\right)$ as given (Equation (8)), was found to lies between 0 and 1 indicating that adsorption of As(V) by MNPS is favorable [35].

$$
R_{L}=\frac{1}{1+b C_{0}}
$$

In addition to this, the equilibrium uptake capacity for both the models was determined by using the investigated parameters and plotted together with experimental $\mathrm{As}(\mathrm{V})$ uptake capacity as shown in Figure 10. The result from this figure

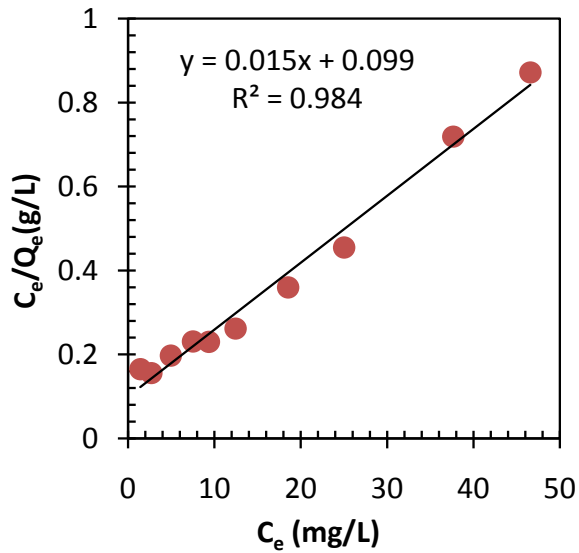

(a)

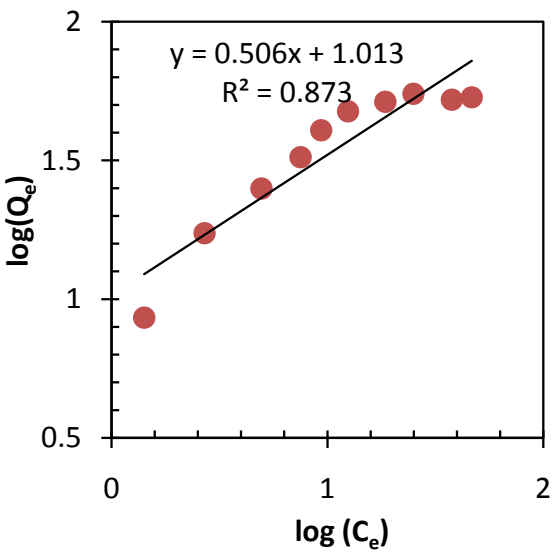

(b)

Figure 9. Adsorption isotherms of MNPs for As(V) adsorption (a) Langmuir, and (b) Freundlich model.

Table 2. Langmuir and Freundlich isotherm parameters for the adsorption of As(V) onto MNPs.

\begin{tabular}{|c|c|c|c|c|c|c|c|c|}
\hline \multicolumn{9}{|c|}{ Evaluated isotherm parameter for the removal of $A s(V)$ using MNPs } \\
\hline \multicolumn{5}{|c|}{ Langmuir Model } & \multicolumn{4}{|c|}{ Freundlich Model } \\
\hline$Q_{\max .}(\mathrm{mg} / \mathrm{g})$ & $b(\mathrm{~L} / \mathrm{mg})$ & $R^{2}$ & $\Delta G\left(\mathrm{KJ} \cdot \mathrm{mol}^{-1}\right)$ & $x^{2}$ & $K_{f}\left[(\mathrm{mg} / \mathrm{g})(\mathrm{L} / \mathrm{mg})^{1 / \mathrm{n}}\right]$ & $1 / n$ & $R^{2}$ & $x^{2}$ \\
\hline 62.89 & 0.159 & 0.98 & -23.52 & 3.28 & 10.31 & 0.507 & 0.87 & 15.41 \\
\hline
\end{tabular}




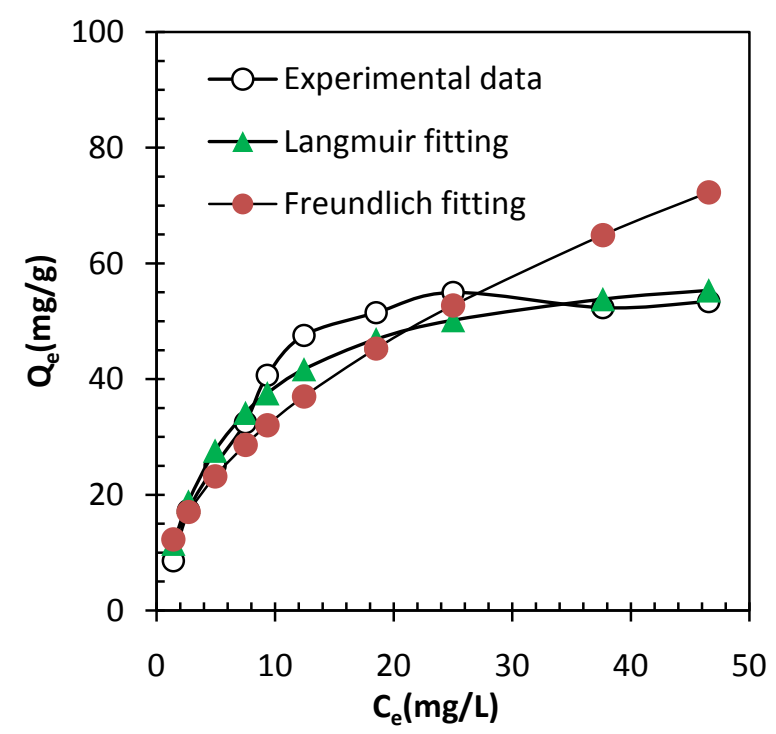

Figure 10. Adsorption isotherm plots for the adsorption of $\mathrm{As}(\mathrm{V})$ onto MNPs.

shows that the equilibrium $\mathrm{As}(\mathrm{V})$ uptake capacity evaluated from Langmuir isotherm model is more close than Freundlich model, suggesting that monolayer of $\mathrm{As}(\mathrm{V})$ was formed on the surface of MNPs during adsorption process. Moreover, the Langmuir constant $b$ is combining to free energy change of adsorption $\Delta G\left(\mathrm{~kJ} \cdot \mathrm{mol}^{-1}\right)$ by the following relation [36] (Equation (9)) and is a critical factor for determining the spontaneity of a process.

$$
\Delta G=-R T \ln (b * M * 1000)
$$

The value of $\Delta G$ was found to be $-23.52 \mathrm{~kJ} \cdot \mathrm{mol}^{-1}$. The negative value of free energy change $(\Delta G)$ in adsorption process reveals the spontaneous nature and feasibility of the adsorption process for the adsorption of $\mathrm{As}(\mathrm{V})$ onto MNPS. The observed value of $\Delta G$ confirms the adsorption process is favored by physio-chemical adsorption for $\mathrm{As}(\mathrm{V})$ ion.

\section{7) Comparision of Maximum adsorption capacity of $A s(V)$ ions}

The adsorption capacity of the adsorbent largely depends on different parameters such as particle size, surface morphology and $\mathrm{pH}$ of the solution. Table 3 shows the comparison of the maximum adsorption capacity of MNPs investigated in this study for $\mathrm{As}(\mathrm{V})$ with other adsorbents reported in the literature. As can be observed from the results of this table that the non-modified iron oxide NPs [8] alone have very low adsorption capacity where as it is increased by chemical modification [9]. The metal loaded adsorbents, magnetic iron oxide NPs and MNPs possesses high adsorption capacity than other adsorbents [30] [34] [35] [36]. Magnetite nanoparticles (MNPs) investigated in this study have competitive adsorption potential for $\mathrm{As}(\mathrm{V})$ ion. Therefore it can be a promising alternative for the remediation of aqueous solution polluted with $\mathrm{As}(\mathrm{V})$ ion.

\section{8) Effect of adsorbent dose}

The effect of adsorbent dose on adsorption efficiency of As(V) by MNPs is shown in Figure 11. The maximum removal efficiency increased from $86 \%$ to 
Table 3. A comparison of maximum adsorption of capacity of investigated MNPs for $\mathrm{As}(\mathrm{V})$ with other adsorbents reported in the various literature.

\begin{tabular}{ccccc}
\hline S.N. & Name of sorbents & $\mathrm{pH}$ & $Q_{\max }(\mathbf{m g} / \mathbf{g})$ & References \\
\hline 1 & Iron oxide nanoparticles & 7 & 3.33 & {$[8]$} \\
2 & Ionically modified the iron oxide nanoparticle & 3 & 50.5 & {$[9]$} \\
3 & Bare iron oxide nanoparticle & 3 & 25.1 & {$[9]$} \\
4 & Magnetic iron oxide nanoparticles (MION-Tea) & 7 & 153.8 & {$[30]$} \\
5 & Zr(IV) loaded SOJR & 3.1 & 74.42 & {$[34]$} \\
6 & Tire rubber-alumina composite (TRAL) & 3 & 19.60 & {$[35]$} \\
7 & Activated carbon-alumina composites (ACAL) & 3 & 23.80 & {$[35]$} \\
8 & Fe(III)-treated Staphylococcus xylosus biomass & 3 & 61.34 & [36] \\
9 & Magnetite nanoparticles (MNPs) & 2 & 62.89 & This work \\
\hline
\end{tabular}

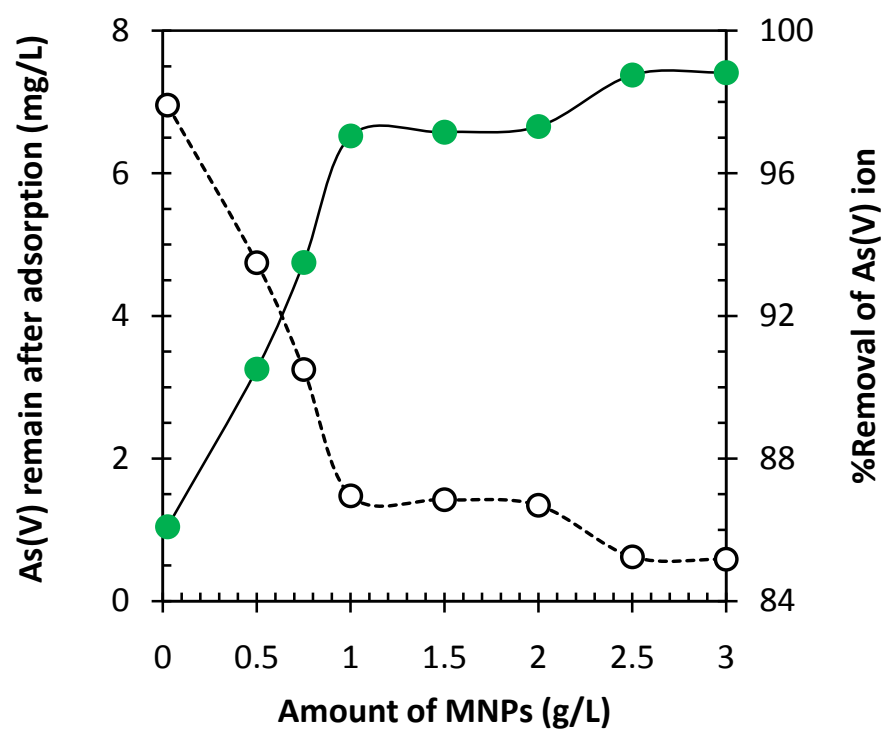

Figure 11. Effect of adsorbent dose for As (V) removal by MNNPs.

$99 \%$ on increasing the adsorbent dose from 0.025 - to $3 \mathrm{~g} / \mathrm{L}$. This is due to availability of more and more surface area of adsorbent for adsorbate at higher dosage. The adsorption of As(V) sharply increased from adsorbent dose $0.025 \mathrm{~g} / \mathrm{L}$ to $1 \mathrm{~g} / \mathrm{L}$, and become slower on further increasing to $2 \mathrm{~g} / \mathrm{L}$ of adsorbent. Adsorption attained equilibrium at adsorbent dosage higher than $2.5 \mathrm{~g} / \mathrm{L}$. It is clear from the result that percentage removal increases on increasing the adsorbent dose but the corresponding value of $\mathrm{As}(\mathrm{V})$ uptake capacity decreased. This is reasonably explained in the fact that the available number of $\mathrm{As}(\mathrm{V})$ ion per unit mass of MNPs decreased with increasing adsorbent dosage, which caused the decrease of $\mathrm{As}(\mathrm{V})$ uptake capacity at higher dosage.

\section{Conclusion}

In this research work, MNPs were successfully synthesized by using aqueous 
leaves extracts of Azadirachta indica (neem). Using prepared MNPs as adsorbent for removal arsenate in synthetic water sample revealed that the maximum adsorption capacity of As (V) was found to be $62.89 \mathrm{mg} / \mathrm{g}$ at optimum $\mathrm{pH}$ 2. The kinetic data were best fitted to the pseudo-second order kinetic model with rate constant $0.0052 \mathrm{~g} \mathrm{mg}^{-1} \cdot \mathrm{min}^{-1}$. The calculated Gibb's free energy $(\Delta G=-23.25$ $\mathrm{KJ} \cdot \mathrm{mol}^{-1}$ suggested that the sorption of arsenic onto MNPs is spontaneous in nature. The values of $\chi^{2}$ and $R^{2}$ concluded that the adsorption of As (V) followed the Langmuir adsorption isotherm. Moreover, adsorption $\mathrm{As}(\mathrm{V})$ was favored by electrostatic attraction between positively charged adsorbent surface and anions of arsenate species in aqueous solution as the $\mathrm{pH}_{\mathrm{PZC}}$ of magnetite nanoparticle was found to be 7.5. Hence, biosynthesized of MNPs using locally available aqueous green (leaves extract of Azadirachta indica) resources is a simple, environmentally friendly, and cost-effective approach as well as it could be a potential adsorbent for arsenate removal from polluted water.

\section{Acknowledgements}

Authors are thankful to Mr. Bipin Dahal, a PhD scholar, Department of BIN Convergence Technology, Chonbuk National University, Jeonju, Republic of Korea for SEM images.

\section{Conflicts of Interest}

The authors declare no conflicts of interest regarding the publication of this paper.

\section{References}

[1] Ali, H., Khan, E. and Ilahi, I. (2019) Environmental Chemistry and Ecotoxicology of Hazardous Heavy Metals: Environmental Persistence, Toxicity, and Bioaccumulation. Journal of Chemistry, 2019, Article ID: 6730305. https://doi.org/10.1155/2019/6730305

[2] Mohan, D. and Pittman, C.U. (2006) Activated Carbons and Low Cost Adsorbents for Remediation of Tri- and Hexavalent Chromium from Water. Journal of Hazardous Materials, 137, 762-811. https://doi.org/10.1016/j.jhazmat.2006.06.060

[3] World Health Organization (2017) Guidelines for Drinking Water Quality. WHO Guidelines 315, WHO, Geneva.

[4] Okazaki, T., Wang, W., Kuramitz, H., Hata, N. and Taguchi, S. (2013) Molybdenum Blue Spectrophotometry for Trace Arsenic in Ground Water Using a Soluble Membrane Filter and Calcium Carbonate Column. Analytical Sciences, 29, 67-72. https://doi.org/10.2116/analsci.29.67

[5] Liu, C.-H., Chuang, Y.-H., Chen, T.-Y., Tian, Y., Li, H., Wang, M.-K. and Zhang, W. (2015) Mechanism of Arsenic Adsorption on Magnetite Nanoparticles from Water: Thermodynamic and Spectroscopic Studies. Environmental Science and Technology, 49, 7726-7734. https://doi.org/10.1021/acs.est.5b00381

[6] Manning, B.A., Fendorf, S.E. and Goldberg, S. (1998) Surface Structures and Stability of Arsenic(III) on Goethite: Spectroscopic Evidence for Inner-Sphere Complexes. Environmental Science and Technology, 32, 2383-2388. https://doi.org/10.1021/es9802201 
[7] Mishra, S.P. (2014) Adsorption-Desorption of Heavy Metal Ions. Current Science, 107, 601-612.

[8] Prathna, T.C., Sharma, S.K. and Kennedy, M. (2017) Development of Iron Oxide Nanoparticle Adsorbents for Arsenic and Fluoride Removal. Desalination and Water Treatment, 67, 187-195. https://doi.org/10.5004/dwt.2017.20464

[9] Badruddoza, A.Z.M., Shawon, Z.B.Z., Rahman, M.T., Hao, K.W., Hidajat, K. and Uddin, M.S. (2013) Ionically Modified Magnetic Nanomaterials for Arsenic and Chromium Removal from Water. Chemical Engineering Journal, 225, 607-615. https://doi.org/10.1016/j.cej.2013.03.114

[10] Yang, J., Hou, B., Wang, J., Tian, B., Bi, J., Wang, N., Li, X. and Huang, X. (2019) Nanomaterials for the Removal of Heavy Metals from Wastewater. Nanomaterials, 9, 424. https://doi.org/10.3390/nano9030424

[11] Habuda-Stanic, M. and Nujic, M. (2015) Arsenic Removal by Nanoparticles: A Review. Environmental Science and Pollution Research, 22, 8094-8123. https://doi.org/10.1007/s11356-015-4307-Z

[12] Chen, W., Parette, R., Zou, J., Cannon, F.S. and Dempsey, B.A. (2007) Arsenic Removal by Iron-Modified Activated Carbon. Water Research, 41, 1851-1858.

[13] Salviano, L.B., Da Silva Cardoso, T.M., Silva, G.C., Silva Dantas, M.S. and De Mello Ferreira, A. (2018) Microstructural Assessment of Magnetite Nanoparticles $\left(\mathrm{Fe}_{3} \mathrm{O}_{4}\right)$ Obtained by Chemical Precipitation under Different Synthesis Conditions. Materials Research, 21, 2-8. https://doi.org/10.1590/1980-5373-mr-2017-0764

[14] Siddiqi, K.S., ur Rahman, A., Tajuddin and Husen, A. (2016) Biogenic Fabrication of Iron/Iron Oxide Nanoparticles and Their Application. Nanoscale Research Letters, 11, Article No. 498. https://doi.org/10.1186/s11671-016-1714-0

[15] Khalil, A.T., Ovais, M., Ullah, I., Ali, M., Khan S.Z. and Maaza, M. (2017) Biosynthesis of Iron Oxide $\left(\mathrm{Fe}_{2} \mathrm{O}_{3}\right)$ Nanoparticles via Aqueous Extracts of Sageretia thea (Osbeck.) and Their Pharmacognostic Properties. Green Chemistry Letters and Reviews, 10, 186-201. https://doi.org/10.1080/17518253.2017.1339831

[16] Hussain, I., Singh, N.B., Singh. A., Singh, H. and Singh, S.C. (2016) Green Synthesis of Nanoparticles and Its Potential Application. Biotechnoogyl Letters, 38, 545-560.

[17] El-Kassas, H.Y., Aly-Eldeen, M.A. and Gharib, S.M. (2016) Green Synthesis of Iron Oxide $\left(\mathrm{Fe}_{3} \mathrm{O}_{4}\right)$ Nanoparticles Using Two Selected Brown Seaweeds: Characterization and Application for Lead Bioremediation. Acta Oceanologica Sinica, 35, 89-98. https://doi.org/10.1007/s13131-016-0880-3

[18] Loo, Y.Y., Chieng, B.W., Nishibuchi, M. and Radu, S. (2012) Synthesis of Silver Nanoparticles by Using Tea Leaf Extract from Camellia sinensis. International Journal of Nanomedicine, 7, 4263-4267. https://doi.org/10.2147/I]N.S33344

[19] Herlekar, M., Barve, S. and Kumar, R. (2014) Plant-Mediated Green Synthesis of Iron Nanoparticles. Journal of Nanoparticles, 2014, Article ID: 140614. https://doi.org/10.1155/2014/140614

[20] Rosli, I.R., Zulhaimi, H.I., Ibrahim, S.K.M., Gopinath, S.C.B., Kasim, K.F., Akmal, H.M., Nuradibah, M.A. and Sam, T.S. (2018) Phytosynthesis of Iron Nanoparticle from Averrhoa Bilimbi Linn. IOP Conference Series: Materials Science and Engineering, 318, 1-9. https://doi.org/10.1088/1757-899X/318/1/012012

[21] Mohanpuria, P., Rana, N.K. and Yadav, S.K. (2008) Biosynthesis of Nanoparticles: Technological Concepts and Future Applications. Journal of Nanoparticle Research, 10, 507-517. https://doi.org/10.1007/s11051-007-9275-x

[22] Kanagasubbulakshmi, S. and Kadirvelu K. (2017) Green Synthesis of Iron Oxide 
Nanoparticles Using Lagenaria siceraria and Evaluation of Its Antimicrobial Activity. Defence Life Science Journal, 2, 422-427. https://doi.org/10.14429/dlsj.2.12277

[23] Lingamdinne, L.P., Chang, Y.Y., Yang J.K., Singh, J., Choi, E.H., Shiratani, M., Koduru, J.R. and Attri, P. (2017) Biogenic Reductive Preparation of Magnetic Inverse Spinel Iron Oxide Nanoparticles for the Adsorption Removal of Heavy Metals. Chemical Engineering Journal, 307, 74-84. https://doi.org/10.1016/j.cej.2016.08.067

[24] Mahdavi, M. Ahmad, M.B., Haron, J., Namvar, F., Nadi, B., Zaki, M.R. and Amin, J. (2013) Synthesis, Surface Modification and Characterisation of Biocompatible Magnetic Iron Oxide Nanoparticles for Biomedical Applications. Molecules, 18, 7533-7548. https://doi.org/10.3390/molecules 18077533

[25] Fiol, N. and Villaescusa, I. (2009) Determination of Sorbent Point Zero Charge: Usefulness in Sorption Studies. Environmental Chemistry Letters, 7, 79-84. https://doi.org/10.1007/s10311-008-0139-0

[26] Choudhury, R., Majumder, M., Roy, D.N., Basumallick, S. and Misra, T.K. (2016) Phytotoxicity of Ag Nanoparticles Prepared by Biogenic and Chemical Methods. International Nano Letters, 6, 153-159. https://doi.org/10.1007/s40089-016-0181-Z

[27] Paudyal, H., Ohto, K., Kawakita, H. and Inoue, K. (2020) Recovery of Fluoride from Water through Adsorption Using Orange-Waste Gel, Followed by Desorption Using Saturated Lime Water. Journal of Material Cycles and Waste Management, 22, 1484-1491. https://doi.org/10.1007/s10163-020-01042-1

[28] Awwad, A.M. and Salem, N.M. (2012) A Green and Facile Approach for Synthesis of Magnetite Nanoparticles. Nanoscience and Nanotechnology, 2, 208-213. https://doi.org/10.5923/j.nn.20120206.09

[29] Khandanlou, R. Ahmad, M.B., Shameli, K. and Kalantari, K. (2013) Synthesis and Characterization of Rice Straw $/ \mathrm{Fe}_{3} \mathrm{O}_{4}$ Nanocomposites by a Quick Precipitation Method. Molecules, 18, 6597-6607. https://doi.org/10.3390/molecules18066597

[30] Lunge, S., Singh, S. and Sinha, A. (2014) Magnetic Iron Oxide $\left(\mathrm{Fe}_{3} \mathrm{O}_{4}\right)$ Nanoparticles from Tea Waste for Arsenic Removal. Journal of Magnetism and Magnetic Materials, 356, 21-31. https://doi.org/10.1016/j.jmmm.2013.12.008

[31] Phumying, S., Labuayai, S., Thomas, C., Amornkitbamrung, V., Swatsitang, E. and Maensiri, S. (2013) Aloevera Plant-Extracted Solution Hydrothermal Synthesis and Magnetic Properties of Magnetite $\left(\mathrm{Fe}_{3} \mathrm{O}_{4}\right)$ Nanoparticles. Applied Physics A: Materials Science and Processing, 111, 1187-1193. https://doi.org/10.1007/s00339-012-7340-5

[32] Poudel, B.R., Aryal, R.L., Bhattarai,S., Koirala, A.R., Gautam, S.K., Ghimire, K.N., Pant, B., Park, M., Paudyal, H. and Pokhrel, M.R. (2020) Agro-Waste Derived Biomass Impregnated with $\mathrm{TiO}_{2}$ as a Potential Adsorbent for the Removal of As(III) from Water. Catalysts, 10, 1125. https://doi.org/10.3390/catal10101125

[33] Paudyal, H., Inoue, K., Ohto, K., Kawakita, H. and Harada, H. (2019) Recovery of Phosphorus from Incineration Ash of Chicken Dropping by Citric Acid Leaching Followed by Adsorption Using Porous Resin Containing Hydrated Zirconium Oxide Powder. Journal of Chemical Engineering of Japan, 52, 465-470.

[34] Ghimire, K.N., Inoue, K., Makino, K. and Miyajima, T. (2002) Adsorptive Removal of Arsenic Using Orange Juice Residue. Separation Science and Technology, 37, 2785-2799. https://doi.org/10.1081/SS-120005466

[35] Karmacharya, M.S., Gupta, V.K, Tyagi, I., Agarwal, S. and Jha, V.K. (2016) Removal of As(III) and As(V) Using Rubber Tire Derived Activated Carbon Modified with Alumina Composite. Journal of Molecular Liquids, 216, 836-844.

https://doi.org/10.1016/j.molliq.2016.02.025 
[36] Aryal, M., Ziagova, M. and Liakopoulou-Kyriakides, M. (2011) Comparison of $\mathrm{Cr}(\mathrm{VI})$ and $\mathrm{As}(\mathrm{V})$ Removal in Single and Binary Mixtures with Fe(III)-Treated Staphylococcus xylosus Biomass: Thermodynamic Studies. Chemical Engineering Journal, 169, 100-106. https://doi.org/10.1016/j.cej.2011.02.059 